\title{
THE MM-WAVE SHEET BEAM KLYSTRON: PERFORMANCE AT DIFFERENT VOLTAGES
}

\author{
S. Solyga, M. Schmolke and H. Henke* \\ Technische Universität Berlin, EN2, Einsteinufer 17, D-10587 Berlin, Germany
}

\section{Abstract}

The aim of our work is the design of a simple and light, small and cheap mm-wave source with moderate power. Our choice has been a $25 \mathrm{kV}$ PPM-focused sheet beam klystron (SBK). However, the efficiency predicted for such a device is very poor: A low beam voltage means small coupling coefficients and a sheet beam profile means a gun with one-dimensional compression only resulting in a low current density. Thus, the performance can be improved by either splitting the wide beam into several round beams with higher current density, or by raising the beam voltage. In this paper the performance of a 25,50 and $100 \mathrm{kV}$ $\mathrm{mm}$-wave SBK is investigated. Simulation results for the electron guns and the cavity resonantors are presented and an overview on the predicted electrical parameters is given.

\section{INTRODUCTION}

The concept of a low voltage sheet beam implies several advantages which led to our choice of a $25 \mathrm{kV}$ PPM focused SBK: A low voltage drastically reduces the requirements of $\mathrm{X}$-ray shielding and power supply while a flat beam is well adapted for modern microfabricational techniques where a planar geometry is necessary. The moderate level of current density permits focusing using a light periodic permanent magnet structure.

Unfortunately, opposed to the advantages inherent in a low voltage sheet beam concept is the drawback of a low efficiency resulting from a low current density and a small shunt impedance value. A low beam velocity degrades the shunt impedance for two reasons: the transit angle as well as the transverse dependence of the impedance is increased. The best possible efficiency within reach for a $25 \mathrm{kV}$ PPM focused SBK was predicted to be approximately $10 \%$ (without making use of a depressed collector). A way to improve this situation is going to higher voltages. Within the present study simulations have been performed to examine what gain in klystron performance may be achieved by raising the beam voltage. Due to the high aspect ratio of the beam (25:1), a twodimensional treatment yields good approximation results and is used throughout this paper.

\footnotetext{
*henke@TU-Berlin.DE
}

\section{ELECTRON GUN SIMULATIONS}

Basis for the electron guns considered here is a design of a $25 \mathrm{kV}$ electron gun providing a sheet beam of $400 \mu \mathrm{m}$ thickness and current of $1.9 \mathrm{~A} / \mathrm{cm}$ at a cathode loading of less than $5 \mathrm{~A} / \mathrm{cm}^{2}$, [1]. The implemented modulation anode allows nearly powerless beam switching for pulsed operation while keeping the costs for the power supply at a moderate level. Together with the anode it forms an electrostatic lense thus heavily increasing the compression up to a ratio of 10:1. Keeping the number of electrodes included small and their shapes as simple as possible is expected to reduce the manufacturing costs.

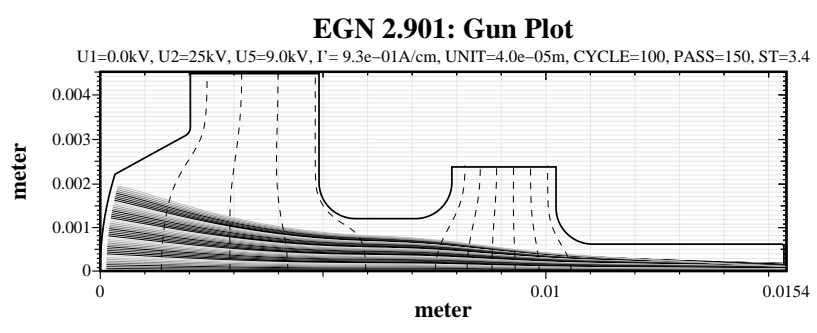

EGN 2.901: Gun Plot

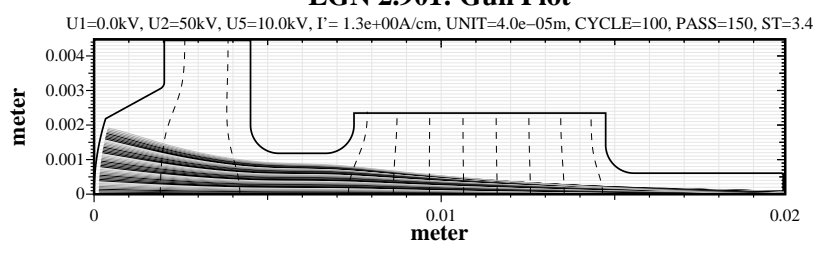

EGN 2.901: Gun Plot

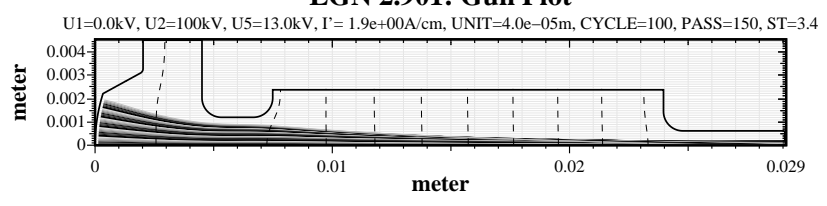

Figure 1: Vertical cut of $25 \mathrm{kV}, 50 \mathrm{kV}$ and $100 \mathrm{kV}$ electron gun

Starting with an anode voltage $V_{0}$ of $25 \mathrm{kV}$ its value was increased in two steps to $50 \mathrm{kV}$ and $100 \mathrm{kV}$. One way would have been simply scaling all the voltages leading to a modanode voltage of $36 \mathrm{kV}$ in case of $100 \mathrm{kV}$ applied to the anode. Since we prefer a low modanode voltage switching the beam we did not further follow this idea. The minimum electrode spacing $d_{\text {min }}$ between modulation anode and anode necessary to avoid electrical breakdown 
was determined using Kilpatrick's criterion [2] and a relationship given by Staprans [3] as a guideline which reads in the worst case (D.C. operation and beam switched off) $d_{\min }=\left(V_{0} / 3 \cdot 10^{6}\right)^{1.25}$ with $d_{\min }$ and $V_{0}$ taken in MKS units leading to $2.5 \mathrm{~mm}, 6.0 \mathrm{~mm}$ and $14.2 \mathrm{~mm}$ spacing for $25 \mathrm{kV}, 50 \mathrm{kV}$ and $100 \mathrm{kV}$ anode voltage, respectively.

In order to keep the already achieved beam shape and compression ratio nearly unchanged while varying the anode voltage, the voltage and position of the modulation anode was carefully adapted. This was accomplished performing simulations using the electron optics code EGUN. Figure 1 shows a vertical cut of the three guns under investigation together with the according electron trajectories and equipotentials. The obtained results apparently exhibit that the beam thickness of $0.4 \mathrm{~mm}$ can be maintained while the beam current increases to $2.6 \mathrm{~A} / \mathrm{cm}$ in case of the $50 \mathrm{kV}$ beam and to $3.8 \mathrm{~A} / \mathrm{cm}$ for the $100 \mathrm{kV}$ beam. The corresponding modanode voltages required are $10 \mathrm{kV}$ and $13 \mathrm{kV}$ only and the cathode loading amounts to $7 \mathrm{~A} / \mathrm{cm}^{2}$ and $10.2 \mathrm{~A} / \mathrm{cm}^{2}$ respectively.

\section{CAVITY RESONATORS}

The resonator cavities are considered to consist of a certain number of identical simple muffin tin cells, see fig. 2. For each beam voltage, the gap width $g$ has been optimized for maximum shunt impedance at $y=0$ by means of the code GdfidL [4] with the frequency fixed to $91.392 \mathrm{GHz}$.

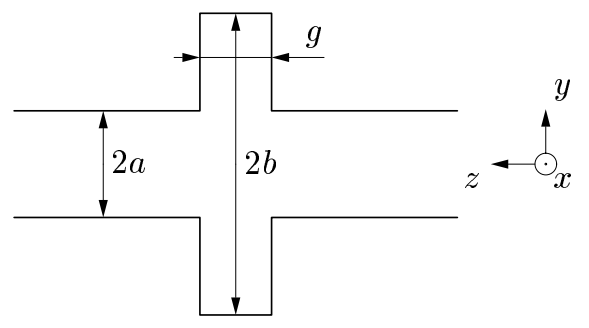

Figure 2: Two-dimensional single cell resonantor

At $25 \mathrm{kV}$, the optimum gap width is $g=0.4 \mathrm{~mm}$ and the shunt impedance is $520 \Omega \mathrm{cm}$. For synchronous operation, a cell distance of $1 \mathrm{~mm}, 0.75 \mathrm{~mm}$ and $0.5 \mathrm{~mm}$ is required for $2 \pi-, 3 \pi / 2$ - and $\pi$-mode, respectively. Correspondingly, within $\lambda_{q} / 16 \approx 5 \mathrm{~mm} 5,7$ and 9 cells can be placed, yielding a total shunt impedance of $2.6 \mathrm{k} \Omega \mathrm{cm}, 3.6 \mathrm{k} \Omega \mathrm{cm}$ and $4.7 \mathrm{k} \Omega \mathrm{cm}$, respectively.

At $50 \mathrm{kV}$, the optimum gap width is $g=0.55 \mathrm{~mm}$ with $2.3 \mathrm{k} \Omega \mathrm{cm}$ shunt impedance. The cell distances are $1.35 \mathrm{~mm}, 1.02 \mathrm{~mm}$ and $0.68 \mathrm{~mm}$ for $2 \pi-, 3 \pi / 2-$ and $\pi$ mode, respectively. Again, assuming a maximum structure length of $\lambda_{q} / 16 \approx 7.5 \mathrm{~mm}, 5,7$ and 11 cells should be realistic, yielding a shunt impedance of 13,18 and $25 \mathrm{k} \Omega \mathrm{cm}$, respectively.

Finally at $100 \mathrm{kV}$, the gap should be $0.75 \mathrm{~mm}$ wide and the shunt impedance predicted for a single cell is $6.5 \mathrm{k} \Omega \mathrm{cm}$. For $2 \pi$-, $3 \pi / 2$ - and $\pi$-mode, the cell spacing must be 1.8 , 1.35 and $0.9 \mathrm{~mm}$, respectively. Within $\lambda_{q} / 16 \approx 12 \mathrm{~mm}$,
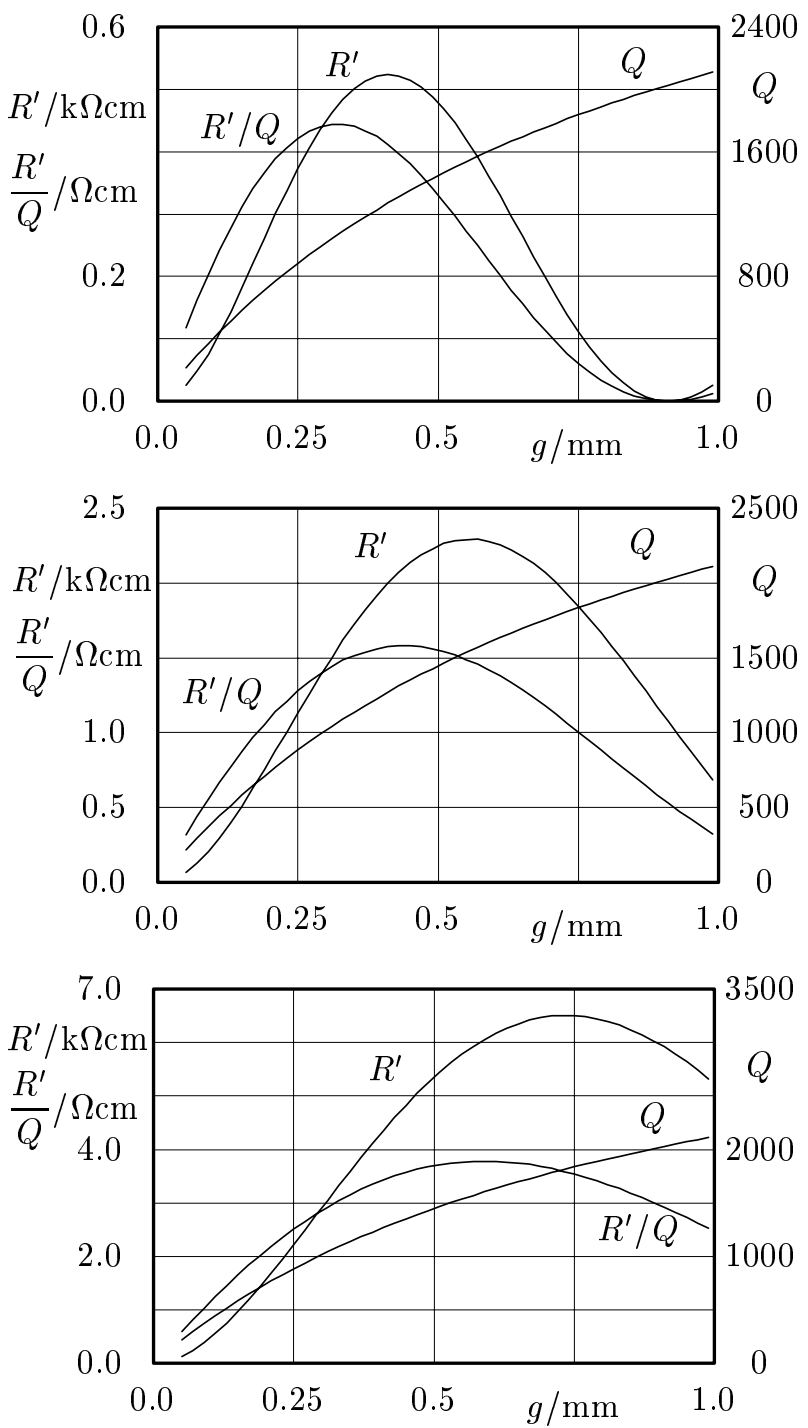

Figure 3: Parameters of the cavity from fig. 2 for 25, 50 and $100 \mathrm{kV}$ beam voltage

6, 9 and 12 cells may be placed, and the total impedance would be 39,58 and $78 \mathrm{k} \Omega \mathrm{cm}$.

\section{PREDICTED EFFICIENCIES}

As shown in [5], the d.c. to r.f. conversion efficiency takes its maximum

$$
\eta=\left\{\begin{array}{ccc}
\frac{m^{2}}{8} \frac{R}{R_{0}} & \text { for } & m R \leq 2 R_{0} \\
\frac{m}{2}-\frac{R_{0}}{2 R} & \text { for } & m R \geq 2 R_{0}
\end{array}\right.
$$

at an external load of

$$
Q_{\text {ext }}=\left\{\begin{array}{ccc}
Q & \text { for } & m R \leq 2 R_{0} \\
Q /\left(m R / R_{0}-1\right) & \text { for } & m R \geq 2 R_{0}
\end{array}\right.
$$

where the lower lines refer to saturation drive. Here, $m$ is the current modulation, $R_{0}$ the beam resistance, $R$ the 
unloaded shunt impedance, $Q$ the unloaded and $Q_{\text {ext }}$ the external quality factor of the resonator.

For all voltages, maximum shunt impedance is achieved at $\pi$-mode, and the predicted efficiencies are $11 \%$ at $25 \mathrm{kV}$, $41 \%$ at $50 \mathrm{kV}$ and $63 \%$ at $100 \mathrm{kV}$. - Saturation drive is possible only at the the higher beam voltages. - The external quality factors required are 1260, 1430 and 490, respectively. Here, a current modulation of 1.6 has been assumed.

\section{REFERENCES}

[1] S. Solyga and H. Henke, "Two-Dimensional Design of a Low Voltage mm-Wave Sheet Beam Klystron”, ITG-Conference:
Displays and Vaccuum Electronics, Garmisch-Patenkirchen, Germany, April 29-30, 1998.

[2] W.D. Kilpatrick, "Criterion of vacuum sparking designed to include both RF and DC", Review of Scientific Instruments, vol. 28, no. 10, October 1957, pp.824-826.

[3] A. Staprans, "Electron gun breakdown", 1985 High-Voltage Workshop, Monterey, CA, Feb. 1985.

[4] W. Bruns, "GdfidL: A Finite Difference Program for Arbitrarily Small Perturbations in Rectangular Geometries" IEEE Trans. on Magn., vol. 32, no. 3, 1453-1456, May 1996

[5] S. Solyga, H. Henke and W. Bruns, "Output Cavity Studies for a Low Voltage mm-Wave Sheet Beam Klystron”, Proceedings of the 6th European Particle Accelerator Conference, June 22-26, 1998

Table 1: Parameter values according to $25 \mathrm{kV}, 50 \mathrm{kV}$ and $100 \mathrm{kV}$ beam voltage, respectively

\begin{tabular}{|c|c|c|c|c|c|c|}
\hline section & parameter & symbol & $25 \mathrm{kV}$ & $50 \mathrm{kV}$ & $100 \mathrm{kV}$ & unit \\
\hline \multirow{6}{*}{ main } & frequency & ff & \multicolumn{3}{|c|}{991.392} & $\overline{\mathrm{GHz}}$ \\
\hline & D.C. input & $P_{0}$ & 47.5 & 130 & 380 & $\mathrm{~kW}$ \\
\hline & rf output & $P$ & 5.2 & 53 & 240 & $\mathrm{~kW}$ \\
\hline & efficiency $\left(I_{r f} / I_{0}=1.6\right)$ & $\eta$ & 11 & 41 & 63 & $\%$ \\
\hline & duty cycle & & \multicolumn{3}{|c|}{$1: 100$} & 1 \\
\hline & pulse width & & \multicolumn{3}{|c|}{1} & $\mathrm{~ms}$ \\
\hline \multirow{12}{*}{ beam } & voltage & $V_{0}$ & 25 & 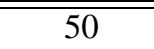 & 100 & $\overline{\mathrm{kV}}$ \\
\hline & current & $I_{0}$ & 1.9 & 2.6 & 3.8 & $\mathrm{~A}$ \\
\hline & beam width & $w$ & \multicolumn{3}{|c|}{10} & $\mathrm{~mm}$ \\
\hline & beam height & $h$ & \multicolumn{3}{|c|}{0.4} & $\mathrm{~mm}$ \\
\hline & current density & $J_{0}$ & 47.5 & 65.0 & 95.0 & $\mathrm{~A} / \mathrm{cm}^{2}$ \\
\hline & perveance per square & $\overline{K_{\square}}$ & 19 & 9.3 & 4.81 & $\mathrm{nP}$ \\
\hline & resistance & $R_{0}$ & 13.2 & 19.2 & 26.3 & $\mathrm{k} \Omega$ \\
\hline & velocity & $v_{0}$ & 0.302 & 0.413 & 0.548 & $c$ \\
\hline & charge density & $\varrho_{0}$ & $5.2 \cdot 10^{-3}$ & $5.2 \cdot 10^{-3}$ & $5.8 \cdot 10^{-3}$ & $\mathrm{C} / \mathrm{m}^{3}$ \\
\hline & plasma frequency & $\omega_{p}$ & 10.2 & 10.2 & 10.7 & $\mathrm{GHz}$ \\
\hline & reduced plasma frequency & $\omega_{q}$ & 7.6 & 6.6 & 5.8 & $\mathrm{GHz}$ \\
\hline & reduced plasma wavelength & $\lambda_{q}$ & 75 & 118 & 178 & $\mathrm{~mm}$ \\
\hline \multirow{5}{*}{ gun } & mod. anode voltage & $\overline{\overline{V_{m}}}$ & $\overline{99}$ & 10 & 13 & $\overline{\mathrm{kV}}$ \\
\hline & cathode width & $\overline{w_{c}}$ & \multicolumn{3}{|c|}{10} & $\mathrm{~mm}$ \\
\hline & cathode height & $h_{c}$ & \multicolumn{3}{|c|}{4.0} & $\mathrm{~mm}$ \\
\hline & cathode loading & $J_{c}$ & 5.0 & 7.0 & 10.3 & $\mathrm{~A} / \mathrm{cm}^{2}$ \\
\hline & beam compression & & \multicolumn{3}{|c|}{$10: 1$} & 1 \\
\hline \multirow{6}{*}{ focusing } & period length & $\overline{\overline{L_{f}}}$ & \multicolumn{3}{|c|}{8.0} & $\overline{\mathrm{mm}}$ \\
\hline & half-aperture & $a_{f}$ & \multirow{2}{*}{\multicolumn{3}{|c|}{$\frac{0.6}{2.0}$}} & $\mathrm{~mm}$ \\
\hline & magnet thickness & $t_{f}$ & & & & $\mathrm{~mm}$ \\
\hline & field amplitude & $B_{0}$ & 60 & 53 & 47 & $\mathrm{mT}$ \\
\hline & pole tip field & $\bar{B}$ & 110 & 94 & 84 & $\mathrm{mT}$ \\
\hline & magnetization & $M$ & 87 & 75 & 67 & $\mathrm{kA} / \mathrm{m}$ \\
\hline \multirow{8}{*}{ cavities } & half-aperture & $\bar{a}$ & \multicolumn{3}{|c|}{0.30} & $\mathrm{~mm}$ \\
\hline & half-depth & $b$ & 0.92 & 0.90 & 0.89 & $\mathrm{~mm}$ \\
\hline & gap length & $g$ & $\overline{0.40}$ & 0.55 & 0.75 & $\mathrm{~mm}$ \\
\hline & shunt resistance p. cell & $R$ & 0.52 & 2.29 & 6.51 & $\mathrm{k} \Omega$ \\
\hline & $\mathrm{R} / \mathrm{Q}$ ratio p. cell & $R / Q$ & 0.42 & 1.48 & 3.52 & $\Omega$ \\
\hline & unloaded quality factor & $Q$ & 1260 & 1545 & 1850 & 1 \\
\hline & external quality factor & $Q_{e x t}$ & 1260 & 1430 & 490 & 1 \\
\hline & number of cells $(\pi$-mode $)$ & $\mathrm{N}$ & 9 & 11 & 12 & 1 \\
\hline
\end{tabular}

